\title{
Research on the Efficiency of Green Technology Innovation in China's Provincial High-End Manufacturing Industry Based on the RAGA-PP-SFA Model
}

\author{
Tuochen Li, Lei Liang $(\mathbb{D}$, and Dongri Han $(\mathbb{D}$ \\ School of Economics and Management, Harbin Engineering University, Harbin 150001, China \\ Correspondence should be addressed to Lei Liang; lianglei1023@126.com
}

Received 16 April 2018; Revised 14 June 2018; Accepted 2 July 2018; Published 15 July 2018

Academic Editor: Luis Martínez

Copyright (C) 2018 Tuochen Li et al. This is an open access article distributed under the Creative Commons Attribution License, which permits unrestricted use, distribution, and reproduction in any medium, provided the original work is properly cited.

\begin{abstract}
This study offers a RAGA-PP-SFA model to measure green technology's innovation efficiency in the high-end manufacturing industry. The study's aim is to solve the shortcomings of traditional SFA methods that are unable to improve multi-output efficiency. The RAGA-PP-SFA model presented here is based on the multi-emission and multi-output characteristics of highend manufacturing innovation activities. Using panel data from 2010 to 2015 on China's high-end manufacturing industry and considering factors such as environmental regulation, government subsidy, and market maturity, this paper empirically examines and compares the efficiency of green technology innovation versus traditional technology innovation, as well as regional heterogeneity in China's high-end manufacturing industry. The study ultimately found a low level of green technology innovation efficiency in China's high-end manufacturing industry. However, an overall rising trend shows that the green development of China's high-end manufacturing industry has achieved remarkable results. Green technology innovation efficiency in high-end manufacturing industries across various regions was generally lower than the efficiency of traditional technology innovation. Both types of efficiency showed a pattern of "high in the east and low in the middle and in the west". High-high efficiency is primarily found in the east, whereas the west is characterized by low-low efficiency. There are significant differences between regions, pointing to an equal rate of development. Government subsidies and enterprise scale had a significant negative impact on green technology innovation efficiency in regional high-end manufacturing industries, while market maturity and industrial agglomeration had a significant positive impact. Based on the study's findings, environmental regulation and openness to the outside world play insignificant roles in green technology innovation efficiency.
\end{abstract}

\section{Introduction}

The high-end manufacturing industry is characterized by high technology and it occupies the high-end segment of the industry chain. High-end manufacturing can be described as critically important, technology-intensive, high-added value, and highly motivating. It is therefore an important indicator of the country's core competitiveness [1]. The Nineteenth Congress' report clearly states that it is necessary to increase manufacturing power and promote the development of advanced manufacturing. The expansion of high-end manufacturing is a new area of growth in China's current and future economic development, and one of the key ways in which China can transform itself into a manufacturing powerhouse. In recent years, China's high-end manufacturing industry has experienced rapid growth with breakthroughs in a number of major technical equipment fields such as manned space flight, manned deep dive, and large-scale aircraft development. These achievements have greatly increased the overall competitiveness of China's manufacturing industry. However, despite these advancements, certain problematic factors can no longer be ignored. For instance, China's high-end manufacturing industry is sizable but not very strong, frequently positioned on the low end of the global value chain. This is due to the country's weak capacity for independent innovation, resulting in low-tech, value-added processing and assembly products. Moreover, China's key manufacturing equipment and core technologies rely heavily on imports.

A continuous increase in China's R\&D (research \& development) investment not only has failed to produce 
corresponding growth, but has also caused a series of problems in terms of resource consumption and environmental pollution. In 2015, the National Council formally announced the "Made in China 2025" campaign to outline important strategic plans for ten high-end fields, emphasizing that we must vigorously strengthen key core technologies and increase the capacity for innovation in key areas. The campaign also called for the full implementation of an efficient, clean, low-carbon, recycled green manufacturing system. Given the global decrease in resources combined with tighter environmental constraints, green technology innovation has become a necessary strategy for China's highend manufacturing industry to gain a competitive edge. Rational and efficient resource allocation and integration are fundamental in green technology innovation. Therefore, a comprehensive evaluation of green technology innovation efficiency in China's high-end manufacturing industries is important and necessary. This paper incorporates energy consumption and environmental pollution into its analytical framework to study the temporal and spatial differences-as well as the influencing factors-in the green technology innovation efficiency of China's high-tech manufacturing. The study also proposes targeted recommendations and a theoretical foundation for China's high-end manufacturing industry, with the purpose of transforming its economic development model and achieving sustainable development.

The remainder of this paper is organized as follows.

Section 2 presents a literature review of green technology innovation efficiency and efficiency evaluation methods; in Section 3, data sources, selection, and variable description are presented; in Section 4, the RAGA-PP model and SFA model are designed; in Section 5, the RAGA-PP model is used to measure the environmental pollution index and the comprehensive output index, and then the SFA model is used to evaluate and analyze the high-end manufacturing green technology innovation efficiency and its influencing factors systematically. Once again, the efficiency of traditional technology innovation in high-end manufacturing is measured, and the two kinds of efficiencies are compared and analyzed. Section 6 is the conclusion and future suggestion.

\section{Literature Review}

Given the global increase in environmental pollution, green technology innovation has gained much worldwide attention. In the field of green performance evaluation, researchers have achieved number of results with important theoretical and practical values, for example, the company's green sustainable innovation capability [2], regional green innovation performance [3], the influence of green innovation on environmental performance and competitive advantage [4], regional high-tech industry innovation ecosystem coordination [5], and so on. More recently, scholars have started to research the relationship between input and output in green production, in other words, green innovation efficiency. For instance, Qian Li and Xiao Renqiao introduced environmental indicators such as three specific industrial wastes and CO2 emissions. Subsequently, they applied common frontier theory and the DEA model to study green technology innovation efficiency and the regional differences among industrial enterprises in various Chinese provinces [6]. Feng Zhijun constructed a DEA-SBM model that can measure undesired output and the green innovation efficiency of industrial Chinese enterprises taking into account the levels of pollutant emissions and energy use [7]. The results of this particular study reveal significant differences in the green innovation efficiency of industrial enterprises above the designated size in China's 30 provincial-level regions and eight economic regions For instance, there is high green innovation efficiency in eastern coastal regions where the economy is relatively developed, but it is of low efficiency in the comparatively poor economies of the northwest and middle and lower reaches of the Yellow River. In another study, Wenxin Wang used the DEA-RAM model to research the unified efficiency and green performance of China's manufacturing innovation [8]. The study's findings show that China's manufacturing systems are progressively shifting to green innovation. Moreover, the level of uniform efficiency observed in the eastern and western regions of China is significantly different and this regional gap continues to grow.

Both domestic and foreign researchers typically use nonparametric and parametric methods to measure efficiency. DEA (data envelopment analysis) is the most commonly used nonparametric method [9]. Many researchers use DEA to evaluate innovation efficiency, including regional innovation efficiency [10-12], industrial technology innovation efficiency [13-15], and high-tech enterprises innovation efficiency [16]. However, when the traditional DEA method is used to measure efficiency, it typically points to technical efficiency as the reason for a smaller actual output (versus a production frontier output). Moreover, the influence of random errors is frequently ignored and it is also impossible to analyze what are the influencing factors of technical efficiency or influencing factors of technological inefficiency. Fried et al. pointed out that the external environment, random factors, and management factors are all elements that affect efficiency [17]. Based on this knowledge, a three-phase DEA model was proposed to remove external environmental factors and random factors $[18,19]$. However, due to the complexity of Jondrow et al's formula [20], operability was poor when this method was used to estimate management inefficiency in the second stage. A parametric method based on the stochastic frontier analysis (SFA) [21] can compensate for the DEA method's inadequacies. This kind of parametric method divides actual output into three parts: production function, random disturbance, and technical inefficiency. At the same time, it can quantitatively analyze the related factors' specific effects on individual differences in efficiency. In another study, Liu Hedong performed a stochastic frontier analysis to measure the overall R\&D efficiency of various Chinese regions and to evaluate the long- and short-term effects of government funding and financial support on R\&D efficiency [22]. Yang Qingfeng used the stochastic frontier model to study the impact of regional export intensity and infrastructure on high-tech industries [23]. Han Jing also applied the stochastic frontier model in order to measure the overall innovation efficiency of China's high-tech industry and of various additional industries. The study's goal was to 
analyze the impact of factors-such as industry profits and total number of companies-on technological innovation efficiency [24].

Despite these achievements, the stochastic frontier model can only analyze the efficiency of a single output and is therefore unable to deal with multiple-output efficiency issues. The present study's main purpose is to solve this problem. Because green technology innovation activities are characterized by multiple emissions and outputs, dimensionality reduction techniques must be used to convert high-dimensional data into low-dimensional data. Therefore, this paper uses RAGAPP (real-coded accelerating genetic algorithm-projection pursuit) to improve the SFA method. We also apply the RAGA-PP-SFA model [25] to measure green technology innovation efficiency in China's high-end manufacturing industry, taking into account environmental factors and random errors. Additionally, this paper analyzes the influence of six factors (environmental regulation, government funding, market maturity, industry concentration, enterprise scale, and openness to the outside world) on efficiency. The study's purpose is ultimately to provide a scientific basis to formulate new policies for high-end manufacturing technology innovation.

\section{Data and Variable Description}

3.1. Data Selection. Based on the study's research purpose and on the available data, variable data such as the input and output of 28 provincial-level high-end manufacturing industries from 2010 to 2015 was selected. Since Tibet, Qinghai, and Hainan have severe data gaps, these three regions were excluded. The study's data sources were the Statistical Yearbook of China Science and Technology, the Statistical Yearbook of High Technology Industry, the China Statistical Yearbook, the China Environmental Statistical Yearbook, and the China Energy Statistical Yearbook.

\subsection{Variable Description}

Input Variables. Investment in green technology innovation activities in the high-end manufacturing industry includes $R \& D$ personnel input and $R \& D$ expenditure, where $R \& D$ personnel input is expressed as full-time equivalents of R\&D. For R\&D expenditure, this paper selected the sum of expenditure in $\mathrm{R} \& \mathrm{D}$ and in new product development as the input index for green technology innovation. Since R\&D expenditure is a flow indicator, it reflects only current R\&D expenditures and thus cannot reflect the cumulative effect of $\mathrm{R} \& \mathrm{D}$ activities. Therefore, the $\mathrm{R} \& \mathrm{D}$ capital stock that lags a phase was selected as the indicator of $R \& D$ expenditure. This paper uses the perpetual inventory method to estimate capital stock [26]. For the base period of 2009, we deflated the selected data [27] and obtained actual values for R\&D expenditure in high-end manufacturing.

Output Variables. The output of green technology innovation in high-tech manufacturing should include specific resources and environmental factors in addition to the general knowledge-benefit output and economic-benefit output, that is, the resource-benefit output and environmentalbenefit output [13]. Invention patents are the direct output of high-end manufacturing R\&D activities and can objectively reflect the industry's technological innovation capabilities and overall technological strength [28]. This study selected the number of patent applications and effective invention patents for each region to represent the knowledge-benefit output of green technology innovation efficiency in highend manufacturing. The ultimate worth of scientific and technological innovation is its commercial value. Therefore, this study uses the sales revenue of high-end manufacturing industries across various regions to represent their economicbenefit output [29]. The resource-benefit output is characterized by the output rate of comprehensive industrial energy consumption, while the environmental-benefit output is represented by the environmental pollution index. This index is obtained, in turn, by measuring industrial water, gas, and solid waste emissions through the projection pursuit method. Since the environmental pollution index represents a negative output, this study treats it as an input indicator for technological innovation [30].

Factors Affecting Efficiency. The factors that influence green technology innovation efficiency include not only innovation factors, but also environmental factors and governmental roles. This study examines the impact of intensity of environmental regulations, government funding, market maturity, industry concentration, enterprise scale, and openness to the outside world [6] on China's high-end manufacturing green technology innovation efficiency.

(1) Intensity of Environmental Regulations. Environmental regulations have both a positive "compensation effect" and a negative "crowding-out effect" on enterprise innovation [31]. Environmental regulation measures require enterprises to carry out technological innovation and improve production processes. Meanwhile, environmental pollution control requires a large amount of capital, which tends to put pressure on a company's R\&D funds. To characterize the intensity of environmental regulations, this paper uses the criterion of investment in pollution governance [32].

(2) Government Funding. Government funding is an important source of financial support for green technology innovation in the high-end manufacturing industry, but its impact on technological innovation has frequently been considered controversial $[33,34]$. On the one hand, the government lacks sufficient cognition on the frontier of technological development and prefers "long-term" technology research and development. On the other hand, the government's capital investment in enterprises' technological innovation lacks a sound fund management mechanism, leading to the occasional occurrence of rent-seeking activities. To some extent, this inhibits companies' R\&D activities. Throughout this paper, government funds obtained through R\&D fundraising activities represent government funding.

(3) Market Maturity. The market is a platform for the flow of knowledge, technology, and optimized allocation of 
resources. The higher the maturity of the regional technology market, the easier to promote communication and cooperation between technology seekers and suppliers, which in turn encourages the use of technology and a stable rate of scientific and technological advancements. Combining the available data, this paper uses a ratio of technical market transaction volume to regional GDP.

(4) Industry Concentration. When the number of highend manufacturing enterprises increases, a good symbiotic relationship must be established between enterprises to enable the sharing of infrastructure and other resources. This reduces companies' costs in terms of raw materials, transportation, procurement, and other expenses. Information sharing among enterprises fosters a strong and competitive market environment. At the same time, technology diffusion [35] promotes enterprises' mutual learning and improves technological innovation efficiency. This paper uses the proportion of each region's high-end manufacturing companies to the total number of regional companies as a measure of the degree of industrial aggregation.

(5) Enterprise Scale. The influence of enterprise size on technological innovation efficiency has not got a consistent conclusion been comprehensively evaluated. Large-scale, highend manufacturing companies typically possess sufficient $\mathrm{R} \& \mathrm{D}$ funds, but, due to their large scale, these companies are likely to focus their development on operation and management areas other than R\&D. Ultimately, this prevents them from increasing their R\&D efficiency. Considering that data on high-end manufacturing's total output value cannot be obtained [34], this paper selected a ratio of main business income to number of enterprises as the measure of an enterprise's average size.

(6) Openness to the Outside World. The degree of China's openness to the outside world determines the strength of technology spillover in the international market to a certain extent [24], which helps China's high-end manufacturing companies to observe, digest, imitate, integrate, and re-create advanced foreign technologies. This article uses the proportion of imported, high-tech manufacturing technology expenditure to the regional GDP as a measure of openness.

\section{Research Model}

4.1. Projection Pursuit Model. Projection pursuit is a kind of data processing method that reduces multidimensional data by optimizing the direction of projection. This method aims to reflect an original high-dimensional data structure and features as much as possible, performing global optimization on the original high-dimensional data's projection direction to obtain a one-dimensional optimal projection value [36]. The basic idea of PP is to project high-dimensional data through some kind of combination onto low-dimensional subspaces. For the projected configuration, the projection indicator function (ie, the objective function) is used to measure the probability of the projection of a certain structure. Find the projection values that make the projection index function optimal (that is, reflect high-dimensional data structures or features) and then analyze the structural characteristics of high-dimensional data according to the projection values. The so-called projection is essentially observing data from different angles and looking for the best viewing angle that can best reflect the characteristics of the data and can fully tap the data information, i.e., the optimal projection direction. We used the projection pursuit method to measure environmental pollution index and the comprehensive output index of green technology innovation in high-tech manufacturing. Taking the environmental pollution index as an example, the projection pursuit steps are as follows.

(1) Determine the Projection Value of Environmental Pollution

$$
z(i)_{t}=\sum_{j=1}^{p} a(j)_{t} y(i, j)_{t}
$$

In formula (1), $a(j)_{t}$ represents the projection direction of the variable $j, j=1,2,3$. In the above formula, $z(i)_{t}$ is the projection value of environmental pollution. $y(i, j)_{t}$ is the data of the three pollutants after non-dimensionalization.

\section{(2) Construct the Projection Index Function}

$$
Q(a)=S_{z} D_{z}
$$

In formula (2), $S_{z}$ is the standard deviation of $Z(i)_{t}$ and $D_{z}$ is the local density of $Z(i)_{t}$.

(3) Optimize the Projection Index Function. According to the projection values' scattering characteristics, which require that the local projection points to be as dense as possible, it is preferable to form a number of point clusters and to disperse the overall projection point clusters as much as possible. Subsequently, it is possible to construct an optimization function, which is the maximum value of the projection value variance and local density. Because this is a complex nonlinear function, the projection index function's optimal projection direction and maximum function value are optimized by RAGA (real-coded accelerated genetic algorithm), shown as follows:

$$
\begin{array}{ll}
\max & Q\left(a_{t}\right)=S_{z} D_{z} \\
\text { s.t. } & \sum_{j=1}^{3} a^{2}(j)_{t}=1
\end{array}
$$

(4) Calculate the Environmental Pollution Index. Combining step (3) to obtain a six-year projection of environmental pollution $\mathrm{Z}$ provides the environmental pollution index.

Four outputs of high-tech manufacturing green technology innovation can also be used to calculate a comprehensive output index through the solution steps of the abovementioned projection pursuit model.

4.2. Stochastic Frontier Model. The stochastic frontier model is a parameter-based, stochastic boundary model with a complex disturbance term. Unlike the data envelope analysis method, this model can not only measure technical efficiency 
but also analyze innovative nonefficiency factors. The general expression is as follows:

$$
y_{i t}=f\left(x_{i t}, t\right) \exp \left(v_{i t}-u_{i t}\right)
$$

Take the logarithm of both sides of (4):

$$
\ln y_{i t}=\ln f\left(x_{i t}, t\right)+v_{i t}-u_{i t}
$$

In formula (5), $y_{i t}$ expresses the innovative output in the region $i$ in year $t, x_{i t}$ represents $\mathrm{R} \& \mathrm{D}$ spending, $v_{i t}-u_{i t}$ express error term, and $v_{i t}$ is the random variable. Assuming that $V_{i t} \sim$ $N\left(0, \sigma^{2}\right)$, and is independent with $u_{i t}, u_{i t}$ is a non-negative random variable. Assume that $u_{i t} \sim N\left(m_{i t}, \sigma^{2}\right)$ positive half cutoff distribution and it reflects the inefficiency of production technology, that is, the loss of efficiency of green technology innovation. In order to systematically reflect the variable statistical properties of innovation efficiency, Battese and Coelli [37] set variance parameters $\gamma$; their expression is

$$
\gamma=\frac{\sigma_{u}^{2}}{\sigma_{u}^{2}}+\sigma_{v}^{2}
$$

Equation (6) reflects whether innovation efficiency has statistical characteristics. When $\gamma \longrightarrow 0$, it means that all regions' input and output points are located at the frontier of production. At this time, it is possible to use the least squares method. But when $\gamma \longrightarrow 1$, it indicates that $u$ is the main component of each region's deviation between actual production unit and the production frontier. In this case, the SFA method should be adopted.

This study uses a beyond the logarithm production function, which is more flexible than the Cobb-Douglas production function and can effectively avoid deviations in efficiency estimates due to improper model settings [38]. The beyond logarithmic stochastic frontier model is as follows:

$$
\begin{aligned}
\ln y_{i t}= & \beta_{0}+\beta_{1} \ln l_{i t}+\beta_{2} \ln k_{i t}+\beta_{3} \ln p_{i t}+\beta_{4}\left(\ln l_{i t}\right)^{2} \\
& +\beta_{5}\left(\ln k_{i t}\right)^{2}+\beta_{6}\left(\ln p_{i t}\right)^{2}+\beta_{7} \ln l_{i t} \ln k_{i t} \\
& +\beta_{8} \ln l_{i t} \ln p_{i t}+\beta_{9} \ln k_{i t} \ln p_{i t}+v_{i t}-u_{i t}
\end{aligned}
$$

In formula (7), $y_{i t}$ is the comprehensive output value of green technology innovation; $l_{i t}$ indicates the full-time equivalent of R\&D personnel; $k_{i t}$ expresses R\&D capital stock; $p_{i t}$ expresses environmental pollution index; and $\beta$ is the estimation parameter.

Based on the stochastic frontier production model, we introduced a technology inefficiency function to further analyze the impact of environmental regulation intensity, government funding, market maturity, industry concentration, enterprise scale, and global openness on green technology innovation efficiency in high-tech manufacturing. This can be expressed as follows:

$$
\begin{aligned}
m_{i t}= & \delta_{0}+\delta_{1} E R+\delta_{2} E R^{2}+\delta_{3} G O V+\delta_{4} M M \\
& +\delta_{5} I N A+\delta_{6} E S+\delta_{7} O P E N
\end{aligned}
$$

In (8), $m_{i t}$ represents the mean value of the distribution of technical inefficiencies in the green technology innovation output. ER, GOV, MM, INA, ES, and OPEN represent, respectively, the intensity of environmental regulation, government funding, market maturity, industry concentration, enterprise scale, and openness to the outside world. $\delta$ is the parameter to be evaluated, reflecting the six factors' influence on technical inefficiency. When $\delta<0$, there is a positive impact on the efficiency of green technology innovation. But when $\delta>0$, it means that there is a negative impact on the efficiency of green technology innovation.

\section{Empirical Analysis}

5.1. Environmental Pollution Index and Comprehensive Green Technology Innovation Output Calculation. The best projection direction for the "three wastes" pollution and green technology innovation output for 28 Chinese provinces (from 2010 through 2015) were optimized following the projection pursuit model steps, which were performed through Matlab R2014a software. After this optimization, it was possible to estimate the environmental pollution index and the comprehensive green innovation output index (see Tables 1 and 2). Related parameters are set to population size: population size $n=400$, crossover probability $P_{c}=0.8$, mutation probability $P_{m}=0.1$, and the number of accelerations is 7 .

5.2. Analysis of the Factors Influencing Green Technology Innovation Efficiency in China's High-End Manufacturing Industry. Data from 28 Chinese provincial-level panels from 2010 to 2015 were applied to the beyond the logarithmic stochastic frontier model to calculate green technology innovation efficiency in high-end manufacturing industries in various regions of China. We also measured various factors' impact on efficiency (see Table 3).

$\gamma=0.99$ is significant at the $1 \%$ level, indicating that the SFA method is appropriate. The log-likelihood function value is -94.621 and the maximum likelihood estimation works well. The unilateral LR test value is 71.757 and the overall estimate is valid. In the production function part, R\&D personnel input and R\&D expenditure show a significantly positive impact on green technology innovation at the levels of $1 \%$ and $5 \%$, respectively. The estimated coefficients are 0.573 and 0.352 , respectively. This indicates that $R \& D$ personnel and $\mathrm{R} \& \mathrm{D}$ expenditures are the source of and basic guarantee for technological innovation activities. Good personnel and funding investment will significantly improve the efficiency of green technology innovation in high-end manufacturing industries. In contrast, there is a significantly negative relationship between the environmental pollution index and green technology innovation at the level of $1 \%$. This indicates that environmental pollution is an important factor restricting the improvement of high-tech manufacturing green technology innovation efficiency.

By estimating the efficiency function, we can see that the lag value of government funding negatively impacts green technology innovation efficiency in high-end manufacturing industries at a significant level of $1 \%$. Enterprises' technological innovation is ultimately more dependent on internal 
TABLE 1: Environmental pollution index.

\begin{tabular}{|c|c|c|c|c|c|c|}
\hline \multirow{2}{*}{ Region } & \multicolumn{5}{|c|}{ Year } & \multirow[b]{2}{*}{2015} \\
\hline & 2010 & 2011 & 2012 & 2013 & 2014 & \\
\hline Beijing & 0.00100 & 0.00100 & 0.00100 & 0.00100 & 0.00100 & 0.00100 \\
\hline Tianjin & 0.07249 & 0.06713 & 0.08066 & 0.04282 & 0.08729 & 0.07467 \\
\hline Hebei & 1.40791 & 1.47735 & 1.47831 & 1.38340 & 1.45005 & 1.46947 \\
\hline Shanxi & 0.76970 & 0.77135 & 0.81798 & 0.86174 & 0.78438 & 0.89241 \\
\hline Inner Mongolia & 0.62952 & 0.59712 & 0.62837 & 0.57675 & 0.69104 & 0.81652 \\
\hline Liaoning & 0.69630 & 0.75558 & 0.81468 & 0.72871 & 0.81114 & 0.95577 \\
\hline Jilin & 0.16942 & 0.16684 & 0.18874 & 0.12827 & 0.16622 & 0.18778 \\
\hline Heilongjiang & 0.20674 & 0.17608 & 0.24174 & 0.16736 & 0.21332 & 0.22561 \\
\hline Shanghai & 0.18474 & 0.16327 & 0.17695 & 0.09678 & 0.17755 & 0.15799 \\
\hline Jiangsu & 1.01428 & 0.93209 & 0.97669 & 0.58366 & 1.08518 & 0.95577 \\
\hline Zhejiang & 0.69630 & 0.51746 & 0.55702 & 0.26934 & 0.53435 & 0.46364 \\
\hline Anhui & 0.43794 & 0.49059 & 0.51228 & 0.40573 & 0.52642 & 0.56626 \\
\hline Fujian & 0.46826 & 0.41071 & 0.39502 & 0.28002 & 0.36291 & 0.30845 \\
\hline Jiangxi & 0.34619 & 0.34662 & 0.37439 & 0.32104 & 0.34143 & 0.39328 \\
\hline Shandong & 1.17595 & 0.98098 & 0.97597 & 0.70280 & 1.05037 & 1.08267 \\
\hline Henan & 0.69579 & 0.74240 & 0.74743 & 0.58181 & 0.78438 & 0.71955 \\
\hline Hubei & 0.39742 & 0.41682 & 0.40453 & 0.28482 & 0.40830 & 0.41117 \\
\hline Hunan & 0.39108 & 0.35640 & 0.39292 & 0.26478 & 0.32881 & 0.31167 \\
\hline Guangdong & 0.69769 & 0.59712 & 0.62841 & 0.32937 & 0.62372 & 0.53742 \\
\hline Guangxi & 0.54630 & 0.47997 & 0.51605 & 0.28451 & 0.35845 & 0.30766 \\
\hline Chongqing & 0.18473 & 0.11180 & 0.11835 & 0.09187 & 0.13213 & 0.13266 \\
\hline Sichuan & 0.55103 & 0.44926 & 0.47120 & 0.39630 & 0.43802 & 0.40975 \\
\hline Guizhou & 0.20423 & 0.16440 & 0.22974 & 0.27990 & 0.34587 & 0.28431 \\
\hline Yuanna & 0.27134 & 0.40178 & 0.40453 & 0.40540 & 0.35893 & 0.40138 \\
\hline Shanxi & 0.28935 & 0.23881 & 0.25255 & 0.22333 & 0.28523 & 0.32474 \\
\hline Gansu & 0.07899 & 0.16960 & 0.19937 & 0.16146 & 0.18033 & 0.19996 \\
\hline Nignxia & 0.19508 & 0.09866 & 0.09629 & 0.08171 & 0.12665 & 0.10917 \\
\hline Xinjiang & 0.14138 & 0.15642 & 0.25610 & 0.27382 & 0.33736 & 0.30521 \\
\hline National & 0.46147 & 0.43706 & 0.46205 & 0.36459 & 0.46396 & 0.46450 \\
\hline Eastern area & 0.63540 & 0.57190 & 0.58556 & 0.40991 & 0.59694 & 0.50521 \\
\hline Central area & 0.50635 & 0.52070 & 0.54159 & 0.45332 & 0.52895 & 0.54906 \\
\hline North-east area & 0.35749 & 0.36617 & 0.41505 & 0.34145 & 0.39689 & 0.45639 \\
\hline Western area & 0.30920 & 0.28678 & 0.31726 & 0.27751 & 0.32540 & 0.32914 \\
\hline
\end{tabular}

capital investment than on government support. Meanwhile, enterprise scale has a negative impact on green technology innovation efficiency at a significant level of 5\%. A largerscale high-end manufacturing enterprise is not conducive to improvement in technological innovation efficiency; it seems that the larger the scale is, the more likely the company will focus on areas outside of R\&D. This lack of attention on technology research and development tends to suppress the growth of green technology innovation output.

Market maturity has a positive effect on green technology innovation efficiency at the $1 \%$ level. Technology market maturity directly reflects the commercialization level and economic value of the results of technological innovation. A mature technology market is conducive to improving the efficiency of the transformation of scientific and technological achievements and, subsequently, of green technology innovation.
Industry concentration positively influences green technology innovation efficiency under the significant level of $1 \%$. The top regional high-end manufacturing enterprises can promote technology sharing among other enterprises. This helps to save resources and decrease expenses, leading to the formation of economies of scale, which then increase technology innovation efficiency.

Based on the study's findings, the impact of environmental regulation intensity on technical efficiency is insignificant which is different from the others research [39]. This may be due to the fact that, in the initial stage of environmental regulation, large amounts of funding must be invested to address environmental problems. This consumes R\&D funds and inhibits the improvement of technological innovation efficiency. As environmental regulations gradually mature, the positive effects of environmental governance on efficiency may gradually emerge. 
TABLE 2: High-end manufacturing innovation output projection value.

\begin{tabular}{|c|c|c|c|c|c|c|}
\hline \multirow{2}{*}{ Region } & \multicolumn{6}{|c|}{ Year } \\
\hline & 2010 & 2011 & 2012 & 2013 & 2014 & 2015 \\
\hline Beijing & 0.31290 & 0.39252 & 0.46936 & 0.59609 & 0.65408 & 0.37669 \\
\hline Tianjin & 0.22174 & 0.22299 & 0.31887 & 0.46536 & 0.49658 & 0.21543 \\
\hline Hebei & 0.05876 & 0.06184 & 0.09297 & 0.12114 & 0.18305 & 0.08510 \\
\hline Shanxi & 0.05376 & 0.05233 & 0.09018 & 0.15473 & 0.19621 & 0.02621 \\
\hline Inner Mongolia & 0.05379 & 0.04574 & 0.08692 & 0.19377 & 0.24030 & 0.01687 \\
\hline Liaoning & 0.09179 & 0.12157 & 0.15631 & 0.25587 & 0.30017 & 0.09811 \\
\hline Jilin & 0.05976 & 0.06821 & 0.10662 & 0.27668 & 0.28908 & 0.05318 \\
\hline Heilongjiang & 0.07840 & 0.08726 & 0.12387 & 0.25868 & 0.30701 & 0.06767 \\
\hline Shanghai & 0.32238 & 0.32189 & 0.34423 & 0.46973 & 0.55558 & 0.30239 \\
\hline Jiangsu & 0.56685 & 0.88471 & 0.98671 & 0.92713 & 1.05854 & 1.12439 \\
\hline Zhejiang & 0.25480 & 0.38535 & 0.46924 & 0.55874 & 0.62979 & 0.63580 \\
\hline Anhui & 0.09084 & 0.12802 & 0.18964 & 0.28089 & 0.34986 & 0.21049 \\
\hline Fujian & 0.19024 & 0.21792 & 0.26384 & 0.37478 & 0.42007 & 0.20789 \\
\hline Jiangxi & 0.08604 & 0.09296 & 0.13561 & 0.27678 & 0.32492 & 0.11185 \\
\hline Shandong & 0.22237 & 0.29545 & 0.33025 & 0.27057 & 0.30702 & 0.48692 \\
\hline Henan & 0.06336 & 0.07148 & 0.11253 & 0.27057 & 0.31975 & 0.21541 \\
\hline Hubei & 0.11359 & 0.12660 & 0.15626 & 0.25864 & 0.31434 & 0.18356 \\
\hline Hunan & 0.08039 & 0.11671 & 0.13827 & 0.28350 & 0.33569 & 0.15872 \\
\hline Guangdong & 1.93236 & 1.95210 & 2.01782 & 1.98509 & 2.04051 & 1.99999 \\
\hline Guangxi & 0.06336 & 0.06984 & 0.10426 & 0.23419 & 0.28040 & 0.04098 \\
\hline Chongqing & 0.08865 & 0.11350 & 0.13803 & 0.27575 & 0.32964 & 0.15702 \\
\hline Sichuan & 0.12063 & 0.22797 & 0.27625 & 0.31953 & 0.44246 & 0.22469 \\
\hline Guizhou & 0.08762 & 0.07769 & 0.11639 & 0.26260 & 0.30306 & 0.06840 \\
\hline Yuanna & 0.06268 & 0.06768 & 0.10293 & 0.22909 & 0.26949 & 0.04120 \\
\hline Shanxi & 0.10622 & 0.12405 & 0.16510 & 0.27695 & 0.32789 & 0.10110 \\
\hline Gansu & 0.06993 & 0.06827 & 0.10894 & 0.26999 & 0.31362 & 0.03109 \\
\hline Nignxia & 0.06623 & 0.06624 & 0.10662 & 0.27057 & 0.30717 & 0.02981 \\
\hline Xinjiang & 0.05876 & 0.05723 & 0.08782 & 0.24579 & 0.29379 & 0.02305 \\
\hline National & 0.19922 & 0.23279 & 0.27842 & 0.38083 & 0.43536 & 0.26050 \\
\hline Eastern area & 0.45360 & 0.52609 & 0.58814 & 0.64096 & 0.70502 & 0.58113 \\
\hline Central area & 0.08133 & 0.09802 & 0.13708 & 0.25419 & 0.30680 & 0.15104 \\
\hline North-east area & 0.07665 & 0.09235 & 0.12893 & 0.26374 & 0.29875 & 0.07299 \\
\hline Western area & 0.07779 & 0.09182 & 0.12933 & 0.25782 & 0.31078 & 0.07342 \\
\hline
\end{tabular}

The study's results also showed that degree of openness to the outside world plays no obvious role in green technology innovation in high-tech manufacturing. The introduction of foreign funds to a specific region would likely produce a technology spillover effect in that region $[40,41]$ and would increase its technological innovation output. However, overly relying on foreign technology weakens the momentum of regional independent research and development. Therefore, it would not be conducive to improving green technology innovation efficiency in regional high-end manufacturing industries.

5.3. Comparative Analysis of Green Technology Innovation Efficiency and Traditional Technology Innovation Efficiency in China's High-End Manufacturing Industry. In order to fully investigate the impact of environmental pollution and comprehensive energy consumption on green technology innovation efficiency, we once again applied the RAGA-PPSFA model to measure the efficiency of traditional technologies that do not feature environmental benefits or resource benefits. Since the beyond the logarithm production function did not apply in this case, we selected the Cobb-Douglas production function instead.

Comparative Analysis. According to the model's output results, we measured each region's average efficiency in green technology innovation and traditional technology innovation in high-end manufacturing industries (see Table 4). We also 
TABLE 3: Estimated results of the stochastic frontier production function and efficiency function.

\begin{tabular}{|c|c|c|c|c|c|}
\hline Variable & $\begin{array}{l}\text { Estimated } \\
\text { coefficient }\end{array}$ & T-value & Variable & $\begin{array}{l}\text { Estimated } \\
\text { coefficient }\end{array}$ & T-value \\
\hline $\begin{array}{l}\text { Production } \\
\text { function } \\
\text { constants }\end{array}$ & $0.722 * * *$ & 13.453 & $\begin{array}{l}\text { Efficiency } \\
\text { Function } \\
\text { Constants }\end{array}$ & $-0.594 * *$ & 2.132 \\
\hline $\ln l_{i t}\left(\beta_{1}\right)$ & $0.573 * * *$ & 3.150 & $E R\left(\sigma_{1}\right)$ & 0.0651 & 0.413 \\
\hline $\ln k_{i t}\left(\beta_{2}\right)$ & $0.352 * *$ & 2.132 & $E R^{2}\left(\sigma_{2}\right)$ & -0.012 & 0.498 \\
\hline $\ln p_{i t}\left(\beta_{3}\right)$ & -0.09347 & 0.866 & $G O V\left(\sigma_{3}\right)$ & $0.492 * * *$ & 6.182 \\
\hline$\left(\ln l_{i t}\right)^{2}\left(\beta_{4}\right)$ & -0.189 & 1.562 & $M M\left(\sigma_{4}\right)$ & $-0.480 * * *$ & 5.360 \\
\hline$\left(\ln k_{i t}\right)^{2}\left(\beta_{5}\right)$ & $-0.168 * *$ & 2.034 & $\operatorname{INA}\left(\sigma_{5}\right)$ & $-0.432 * * *$ & 5.025 \\
\hline$\left(\ln p_{i t}\right)^{2}\left(\beta_{6}\right)$ & $-0.157 * * *$ & 2.830 & $E S\left(\sigma_{6}\right)$ & $0.122 * *$ & 2.294 \\
\hline $\ln l_{i t} \ln k_{i t}\left(\beta_{7}\right)$ & $0.450 * *$ & 2.336 & $\operatorname{OPEN}\left(\sigma_{7}\right)$ & -0.034 & 0.611 \\
\hline $\ln l_{i t} \ln p_{i t}\left(\beta_{8}\right)$ & 0.0216 & 0.201 & $\sigma^{2}$ & $0.436 * * *$ & 7.377 \\
\hline \multirow[t]{2}{*}{$\ln k_{i t} \ln p_{i t}\left(\beta_{9}\right)$} & -0.016 & 0.201 & $\begin{array}{c}\gamma \\
\text { Log } \\
\text { likelihood } \\
\text { function } \\
\text { value }\end{array}$ & $0.999 * * *$ & $0.12 \mathrm{E}+08$ \\
\hline & & & $\begin{array}{c}\text { Unilateral LR } \\
\text { test }\end{array}$ & 71.757 & \\
\hline
\end{tabular}

$* * *, * *, *$ represent significant levels at $1 \%, 5 \%$, and $10 \%$, respectively

TABLE 4: Efficiency in green technological innovation and traditional technological innovation in China's provincial high-end manufacturing sector.

\begin{tabular}{|c|c|c|c|c|c|}
\hline Region & $\begin{array}{c}\text { Efficiency of } \\
\text { Traditional } \\
\text { Technological } \\
\text { Innovation }\end{array}$ & $\begin{array}{c}\text { Efficiency of } \\
\text { Green } \\
\text { Technological } \\
\text { Innovation }\end{array}$ & Region & $\begin{array}{c}\text { Efficiency of } \\
\text { Traditional } \\
\text { Technological } \\
\text { Innovation }\end{array}$ & $\begin{array}{c}\text { Efficiency of } \\
\text { Green } \\
\text { Technological } \\
\text { Innovation }\end{array}$ \\
\hline Beijing & 0.97721 & 0.75436 & Hunan & 0.78930 & 0.49899 \\
\hline Tianjin & 0.85186 & 0.65468 & Guangdong & 0.99378 & 0.91920 \\
\hline Hebei & 0.64421 & 0.39499 & Guangxi & 0.70243 & 0.47711 \\
\hline Shanxi & 0.54566 & 0.40687 & Chongqing & 0.90456 & 0.48042 \\
\hline Inner Mongolia & 0.49312 & 0.36364 & Sichuan & 0.87676 & 0.69121 \\
\hline Liaoning & 0.75678 & 0.60686 & Guizhou & 0.63579 & 0.44303 \\
\hline Jilin & 0.79051 & 0.41028 & Yuanna & 0.50515 & 0.45845 \\
\hline Heilongjiang & 0.65100 & 0.43154 & Shanxi & 0.61574 & 0.38062 \\
\hline Shanghai & 0.95516 & 0.67721 & Gansu & 0.43197 & 0.41670 \\
\hline Jiangsu & 0.98864 & 0.84463 & Nignxia & 0.35846 & 0.28840 \\
\hline Zhejiang & 0.79659 & 0.68723 & Xinjiang & 0.21300 & 0.28598 \\
\hline Anhui & 0.74332 & 0.58719 & National & 0.72561 & 0.52480 \\
\hline Fujian & 0.81540 & 0.53602 & Eastern area & 0.85462 & 0.66989 \\
\hline Jiangxi & 0.89139 & 0.49741 & Central area & 0.75851 & 0.48850 \\
\hline Shandong & 0.80785 & 0.56064 & North-east area & 0.73276 & 0.48289 \\
\hline Henan & 0.80973 & 0.54205 & Wenstern area & 0.57370 & 0.42856 \\
\hline Hubei & 0.77165 & 0.39850 & & & \\
\hline
\end{tabular}

drew a corresponding radar chart (see Figure 1). Overall, China's average efficiency in green technology innovation is 0.5248 , while efficiency in traditional technology innovation is 0.7256 (or 20 percentage points higher than green technology innovation efficiency). This shows that energy consumption and environmental pollution have greatly constrained the improvement of green technology innovation efficiency in China's high-end manufacturing industries. Traditional technology innovation efficiency has achieved a complete encirclement of green technology innovation 
TABLE 5: Classification of high-end manufacturing technology innovation efficiency in China's provinces.

Efficiency type
High traditional efficiency and high green efficiency
Low traditional efficiency and high green efficiency
Low traditional efficiency and low green efficiency
High traditional efficiency and low green efficiency

Regions

Beijing, Tianjin, Liaoning, Shanghai, Jiangsu, Zhejiang, Guangdong, Sichuan

Inner Mongolia, Yunnan, Gansu, Ningxia and Xinjiang Hebei, Jilin, Heilongjiang, Anhui, Fujian, Jiangxi, Shandong, Henan, Hubei, Hunan, Guangxi, Chongqing, Guizhou, Shanxi

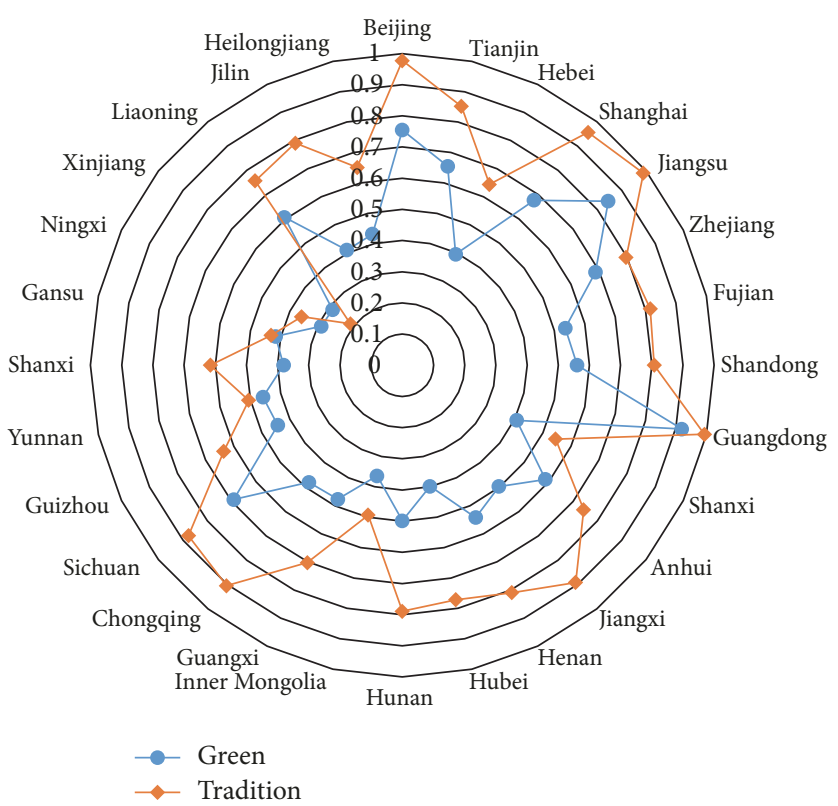

FIGURE 1: Comparison of green technology innovation efficiency and traditional technology innovation efficiency in China's provincial highend manufacturing.

efficiency. However, the distribution trajectories of these two forms of efficiency are similar and the sequencing shows strong consistency, indicating that green and traditional technology innovation efficiencies are closely related.

In terms of provinces and autonomous regions, the rankings of high-tech manufacturing green technology innovation efficiency are as follows (from highest to lowest): Guangdong, Jiangsu, Beijing, Sichuan, and Zhejiang. The top five rankings for traditional technology innovation efficiency are as follows: Guangdong, Jiangsu, Beijing, Shanghai, and Chongqing. Among these, the most obvious aberration is Chongqing, falling from fifth place in traditional technology innovation efficiency to the fifteenth place in green technology innovation efficiency. Additionally, the gap between green and traditional technology innovation efficiencies in Shanghai, Jilin, Jiangxi, and Hubei provinces is greater than 0.3 . This value indicates that these provinces privilege the pursuit of economic benefits in production output and tend to ignore resource and environmental benefits. However, green technology innovation efficiency in high-end manufacturing industries in the western region, represented by Gansu, Ningxia, Yunnan, and Xinjiang, shows little difference from traditional technology innovation efficiency. This might be due to the region's fewer high-end manufacturing companies with relatively smaller environmental pollution and a poor technological innovation base. This issue has resulted in rapid improvement in green management through the partial recreation of developed cities' advanced technologies (see Figure 1).

Efficiency Classification. By measuring the innovation efficiency of both green and traditional technologies in China's high-end manufacturing industry, this study obtained an efficiency classification for high-end manufacturing industries in China's provincial-level regions (see Figure 2).

The 2010-2015 average values of traditional and green innovation efficiency for each provincial level are between 0.21-0.99 and 0.29-0.92, respectively. The two intervals' median value is taken as the vertical line from the horizontal axis to the vertical axis, dividing the plane into four parts: high traditional high green, low traditional high green, low traditional low green, and high traditional low green. Table 5 summarizes the results.

According to Table 5, there are nine regions featuring high green and high traditional technology innovation efficiency in China's high-end manufacturing industry from 2010 to 2015. These are located mostly in the economically developed eastern coastal regions. There are five regions with low green 


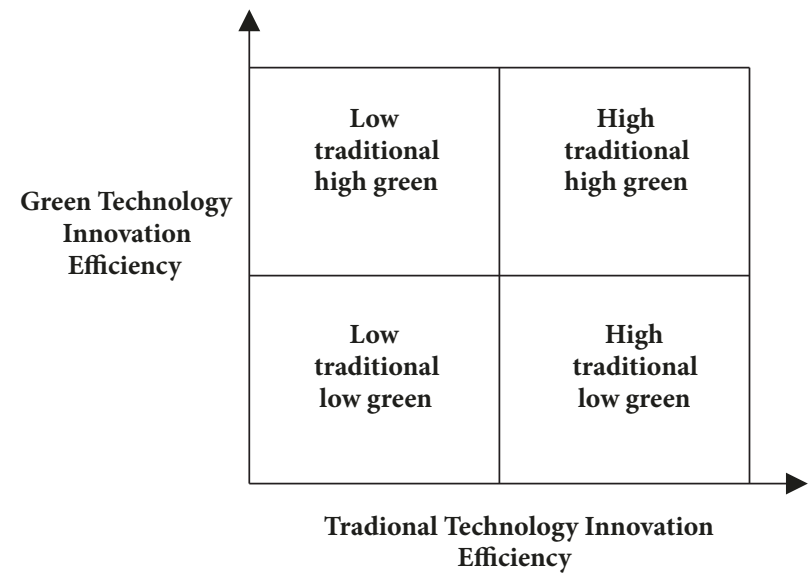

FIGURE 2: 2010-2015 China's provincial district high-end manufacturing technology innovation efficiency classification.

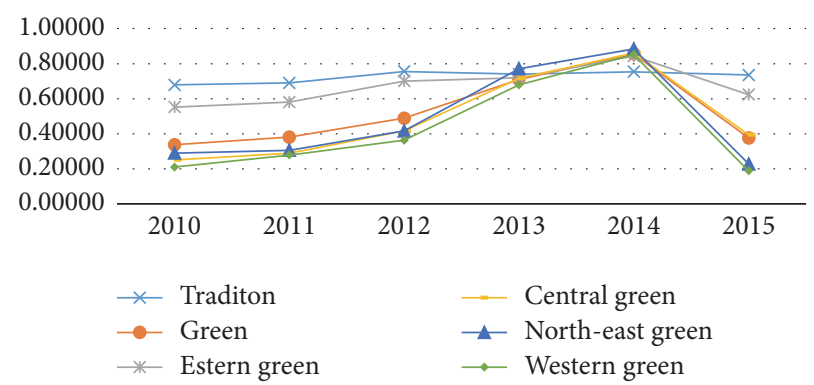

FIgURE 3: Comparison of technology innovation efficiency in China's high-end manufacturing industry.

and low traditional technology innovation efficiency, located in the underdeveloped western regions. There are 14 regions with high traditional and low green efficiency (accounting for half of the country), mainly located in the northeast old industrial bases and the central and western regions.

5.4. Spatial Difference Analysis. As the present study discovered, there are significant regional differences in terms of green technology innovation efficiency in high-end manufacturing. At the regional level, eastern locations feature the highest (0.67) green technology innovation efficiency. Western regions feature the lowest (0.42), revealing a decreasing trend in the eastern, central, northeastern, and western regions. This is in line with the "east-high, west-low" conclusions from prior research. In terms of individual provinces and regions, the most efficient regions in green technology innovation are mainly found in eastern coastal areas, whereas the lowest efficiency regions are in the west including Inner Mongolia, Ningxia, and Xinjiang. The gap between highest and lowest efficiency is 0.633. Overall, regional green development is extremely unbalanced, further explaining the correlation between high-end manufacturing technology and level of economic development. On the one hand, eastern coastal areas are economically and geographically strong due to a high talent density, national tilting policies, and environmental protection policies. All of these qualities create beneficial conditions for green technology innovation in China's high-end manufacturing industries. On the other hand, the long-term science and technology foundations in the midwest and northeast regions are relatively weak. Insufficient investment in R\&D capital, intellectual burnout, high pollution, and energy-intensive industries relying on endowment advantages have all inhibited the improvement of green technology innovation efficiency in high-end manufacturing to varying degrees.

5.5. Time Difference Analysis. Traditional technology innovation efficiency tends to increase steadily, with an average annual efficiency between 0.67 and 0.76 . Efficiency of green technology innovation shows greater volatility, ranging from 0.33 to 0.85 (reaching its highest level in 2014). The average value of green technology innovation efficiency in the highend manufacturing industry in China's central, northeast, and western regions is strikingly similar to the mean fluctuation value of the nation's green technology innovation efficiency. This is also the major contributor to the average nationwide fluctuation over the years. The eastern region's green technology innovation efficiency fluctuates more smoothly, without any major shifts (see Figure 3 ). In recent years, the input-output mechanism of China's high-end manufacturing industry has gradually improved. Moreover, investment in R\&D personnel and funding has gradually become more justifiable, helping to promote the efficiency of China's highend manufacturing traditional technology innovation. Given the intensification of environmental problems, the nation now takes environmental protection very seriously and has 
formulated a number of green regulatory guidelines and environmental protection preferential policies (such as pollution prevention, energy conservation, and emission reduction). The nation has incentivized high-end manufacturing companies to develop innovations in green technology. Consequently, green technology innovation efficiency in China has greatly improved and actually surpassed traditional technology innovation efficiency in 2014. However, the efficiency of both traditional and green technology innovation declined somewhat in 2015. This may be explained by the fact that the nation implemented supply-side structural reforms and controlled part of high-end manufacturing industries' lowend output.

\section{Conclusion and Future Suggestions}

Based on the RAGA-PP-SFA model, this study compares green technology innovation efficiency and traditional technology innovation efficiency in high-end manufacturing industries in 28 Chinese provinces or regions. This paper also explores differences in time and space of high-tech manufacturing green technology innovation efficiency and analyzes the impact of environmental regulatory intensity, government subsidy, market maturity, industry concentration, enterprise scale, and global openness on green innovation efficiency. The study draws the following conclusions and suggestions:

(1) The overall green innovation efficiency of China's high-end manufacturing industry is low. There is a large gap between traditional and green technology innovation efficiencies, but the two complement and promote each other. Lack of resources and the environment issues are significant obstacles that China's high-end manufacturing industries must overcome to achieve sustainable development. Highend manufacturing enterprises in all regions must incorporate the "three wastes" pollutant discharge and energy consumption into their efficiency evaluation systems to correctly estimate their level of green technology innovation efficiency. Continued investments in environmental pollution control, energy-saving techniques, and emission reduction technologies are required to help realize traditional technology innovation, promote green technology transformation, and foster green technology innovation to upgrade traditional industries. Enterprises must actively refine their internal green technology innovation management mechanisms, clarify their economic and environmental responsibilities, and implement relevant policies and regulations for the prevention and control of environmental pollution to improve companies' green management efficiency.

(2) There are significant regional differences in green technology innovation efficiency among China's high-end manufacturing industries. These disparities are consistent with each region's level of economic development. In other words, there is high green technology innovation efficiency in regions with high economic development levels and low green innovation efficiency in regions with low economic development levels. High-end manufacturing industries in eastern coastal areas possess technological, economic, and geographic advantages, resulting in relatively high green technology innovation efficiency. We recommend further development of disruptive technology innovation through technical exchange and cooperation with international high-end manufacturing industries. At the same time, future efforts must implement twinning and offer assistance throughout Midwest and Northeast China. The strong must assist the weak, so high-end manufacturing companies in Midwest and Northeast.

China must be fostered to improve their production processes, equipment, management experience, and technological innovation output. Meanwhile, these companies must make full use of local endowment advantages and beneficial national policies to adjust resource allocation, optimize their industrial structures, focus on improving their capacity for independent innovation, formulate institutional mechanisms for attracting talent, and redesign the green ratios of internal resources. All of these measures will likely increase their green technology innovation efficiency.

(3) The economic development level in China's northeast and middle-western regions is relatively low. Similarly, the region's infrastructure is backward, investment in high-end manufacturing R\&D is low, and human talent is scarce. These disadvantages require the country to provide external support, in the form of funds and policies, for these regions. The nation should formulate innovative policies aimed towards the midwest and northeast regions, such as strategic support through funding and talent recruitment, appropriate flow and fair allocation of innovative resources, and encouragement to all regions to develop independent innovation and achieve collaborative innovation. Simultaneously, the nation must strictly control industrial pollution and improve relevant laws and regulations on environmental pollution to increase the region's level of green technology innovation in high-end manufacturing industries.

The factors of industrial concentration and market maturity positively affect green technology innovation efficiency in regional high-end manufacturing industries, while government funding and enterprise scale have a significant deterrent effect. The national and local governments should take into account regional development advantages and conditions, plan to build high-end manufacturing industrial clusters to save companies' R\&D activity costs, and promote knowledge spillovers. They can also improve the technical market environment and formulate practical and feasible rights protection laws to increase commercialization of scientific and technological advancements. Another useful strategy would be to foster science and technology SMEs by providing necessary financial guarantees and policy support to encourage independent innovation. The government must reevaluate its use of funds to ensure it is fair and efficient. Larger enterprises can strive to streamline and optimize their organizational structures, overcome institutional redundancy, actively gain insights into new changes in the market, and adjust resource allocations.

\section{Data Availability}

(1) The data of R\&D staff input and R\&D funding input used to support the findings of this study have been deposited in 
the China High Technology Statistical Yearbook. (2) The data of patent applications and effective invention patents and new product sales revenue used to support the findings of this study have been deposited in the China High Technology Statistical Yearbook. (3) The data of industrial wastewater, waste gas, and solid waste emissions used to support the findings of this study have been deposited in the China Environmental Statistics Yearbook. (4) The data of comprehensive energy consumption output rate are calculated from energy consumption and output ratio. The data of these two indexes are from China Energy Statistical Yearbook and China Statistical Yearbook, respectively. (5) The data of environmental regulation intensity used to support the findings of this study have been deposited in the China Environmental Statistics Yearbook. (6) The data of government funding and openness to the outside world used to support the findings of this study have been deposited in the China High Technology Statistical Yearbook. (7) The data of market maturity used to support the findings of this study have been deposited in the China Statistical Yearbook. (8) The data of industry concentration are the ratio of high-end manufacturing companies to the total number of regional companies. The data of these two indexes are from China High Technology Statistical Yearbook and China Statistical Yearbook, respectively. (9) The data of enterprise scale is the ratio of main business income to the number of enterprises of high-end manufacturing used to support the findings of this study that have been deposited in the China High Technology Statistical Yearbook.

\section{Conflicts of Interest}

The author declare that there are no conflicts of interest regarding the publication of this paper.

\section{Acknowledgments}

This paper is supported by the National Social Science Fund of China (NSSF) (17ZDA119, 17AGL009) and Central University Fund (HEUCF180904).

\section{References}

[1] Y. F. Cai, H. K. Wei, and L. X. Wu, "Comprehensive Cost Estimation and Sensitivity Analysis of High-end Manufacturing Industry in China," China Industrial Economics, vol. no. 01, pp. 34-44, 2010.

[2] Y. L. Su, H. Y. He, and J. L. Yin, "Research on evaluation system of enterprise green sustainable innovation ability," Science \& Technology Progress and Policy, vol. 26, no. 20, pp. 139-142, 2009.

[3] Z. Hua, "Research on China's green innovation performance: a comparative analysis with the three northeast provinces," Technical Economy, vol. 30, no. 07, p. 30-34+41, 2011.

[4] T. Y. Chiou, H. K. Chan, F. Lettice, and S. H. Chung, "The influence of greening the suppliers and green innovation on environmental performance and competitive advantage in Taiwan," Transportation Research Part E: Logistics and Transportation Review, vol. 47, no. 6, pp. 822-836, 2011.

[5] X. W. He and W. Y. Zhou, "Collaborative classification evaluation of regional innovative ecosystems in high-tech industry," Scientia Sinica, vol. 36, no. 03, pp. 541-549, 2018.
[6] L. Qian, R. Q. Xiao, and Z. W. Chen, "Research on Green Technology Innovation Efficiency and Regional Differences of Industrial Enterprises in China, Based on Common Frontier Theory and DEA Model," Economic Theory and Economic Management, vol. no. 01, pp. 26-43, 2015.

[7] Z. J. Feng, "Research on green innovation efficiency of chinese industrial enterprises," China Science and Technology Forum, vol. no. 02, no. 02, pp. 82-88, 2013.

[8] W. X. Wang, Y. Bo, Y. Xiao et al., "Estimation of innovation's green performance, a range-adjusted measure approach to assess the unified efficiency in China's manufacturing industry," Journal of Cleaner Production, vol. 145, no. 15, pp. 919-924, 2017.

[9] A. Charnes, W. W. Cooper, and E. Rhodes, "Measuring the efficiency of decision making units," European Journal of Operational Research, vol. 2, no. 6, pp. 429-444, 1978.

[10] K. H. Chen and X. L. Fu, "Evaluation of multi-period regional R\&D efficiency, an application dynamic DEA to China's regional R\&D systems," Omega-International Journal of Management Science, vol. 74, pp. 103-114, 2017.

[11] Y. Li, J. H. Bai, and Q. M. Tan, "Empirical analysis of regional innovation efficiency in china, based on provincial panel data and DEA method," Systems Engineering, vol. 26, no. 12, pp. 1-7, 2008.

[12] L. Hong, N. F. Kuang, Y. Wei, W. Di, and X. X. Hong, "Regional environmental efficiency evaluation in China, A-nalysis based on the super-sbm model with undesirable out-puts," Mathematical and Computer Modellong, vol. 58, pp. 1018-1031, 2013.

[13] Z. J. Feng and W. Chen, "Research on the R\&D and innovation efficiency of China's high-tech industry, a new perspective based on resource-constrained two-stage dea model," Systems Engineering - Theory \& Practice, vol. 34, no. 05, pp. 1202-1212, 2014.

[14] H. Liu, Y. F. Liu, W. Qiao, and Y. Hu, "Research on the efficiency of technological innovation in strategic emerging industries in China," Systems Engineering-Theory Practice, vol. 35, no. 09, pp. 2296-2303, 2015.

[15] J. J. Guan and K. H. Chen, "Measurement of the efficiency of technological innovation in high-tech industry in China," Journal of Quantitative Economics and Technology, vol. 26, no. 10, pp. 19-33, 2009.

[16] B. Han, Y. Su, T. Li, and M. Wan, "Study on the technological innovation performance of high-tech enterprises based on twostage DEA," Science Research Management, vol. 39, no. 03, pp. 11-19, 2018.

[17] F. Lovell and S. Yaisawarng, "Accounting for environmental effects and statistical noise data envelopment analysis," Journal of Productivity Analysis, vol. 17, pp. 121-136, 2002.

[18] S. X. Zeng, Y. Yang, and Y. T. Shi, "A Study on the efficiency of high-tech industry in china based on the DEA three-stage model," Economics, vol. 32, no. 01, pp. 116-120, 2013.

[19] W. Liu, "The measurement of R\&D and innovation efficiency of high-tech industry in china-based on the three-phase DEA model," Application of Statistics and Management, vol. 34, no. 01, pp. 17-28, 2015.

[20] J. Jondrow, C. A. Knox Lovell, I. S. Materov, and P. Schmidt, “On the estimation of technical inefficiency in the stochastic frontier production function model," Journal of Econometrics, vol. 19, no. 2-3, pp. 233-238, 1982.

[21] D. Aigner, C. A. K. Lovell, and P. Schmidt, "Formulation and estimation of stochastic frontier production function models," Journal of Econometrics, vol. 6, no. 1, pp. 21-37, 1977. 
[22] H. D. Liu, "Research on regional R\&D efficiency and its influencing factors in china, empirical analysis based on stochastic frontier function," Scientific Researches, vol. 29, no. 04, pp. 548$556,2011$.

[23] Q. F. Yang, "The determinants of R\&D and innovation efficiency in high-tech industry areas, an empirical analysis based on stochastic frontier models," Management Review, vol. 25, no. 06, pp. 47-58, 2013.

[24] J. Han, "Research on china's high-tech industry innovation efficiency-an empirical analysis based on SFA method," Scientific Studies, vol. 28, no. 03, pp. 467-472, 2010.

[25] J. B. Kruskal, "Toward a practical method which help suncover the structure of a set of multivariater obsercations by finding the linear transformation which optimizes a "new index of condensation"," in Statistical Computation, Academia Press, New York, NY, USA, 1969.

[26] Z. Griliches, "R\&D and the productivity slowdow," American Economic Review, no. 70, pp. 343-348, 1980.

[27] Y. B. Wu, "China's Industrial R\&D Output Elasticity Measurement," The Quarterly Journal of Economics, vol. 7, no. 3, pp. 869890, 2008.

[28] X. F. Han, N. Hui, and W. F. Song, "Can information technology improve the efficiency of technological innovation in China's industrial sector?" China Industrial Economics, no. 12, pp. 7082, 2014.

[29] J. A. Schumpeter, Capitalism, Socialism and Democracy, 1943.

[30] P. J. Korhonen and M. Luptacik, "Eco-efficiency analysis of power plants: an extension of data envelopment analysis," European Journal of Operational Research, vol. 154, no. 2, pp. 437446, 2004.

[31] F. X. Jiang, Z. J. Wang, and J. H. Bai, "Dual effects of environmental regulation on technological innovation, an empirical study based on dynamic panel data of jiangsu manufacturing industry," China Industrial Economy, no. 07, pp. 44-55, 2013.

[32] Y. Li, X. H. Dang, X. F. Han, and W. F. Song, "Heterogeneous effects of environmental regulation on long-term and shortterm impacts of technological innovation, a two-stage analysis based on the value chain perspective," Studies in Science of Science, vol. 32, no. 06, pp. 937-949, 2014.

[33] Z. X. Feng, Q. Wang, and X. H. Hou, "Government investment, marketization degree and technological innovation efficiency of Chinese industrial enterprises," Journal of Quantitative Economics and Technology, vol. 28, no. 04, p. 3-17+33, 2011.

[34] W. Xiao and G. B. Lin, "Government support, R\&D management and technological innovation efficiency_- an empirical analysis based on china's industrial industry," Management World, no. 4, pp. 71-80, 2014.

[35] H. C. Yang, L. S. Li, and J. Liu, “The impact of high-tech industry agglomerations on technological innovation and regional comparison," Scientific Studies, vol. 34, no. 02, pp. 212-219, 2016.

[36] J. L. Jin, Y. M. Wei, and J. Ding, "Projection pursuit model for comprehensive evaluation of water quality," Journal of Environmental Sciences, no. 04, pp. 431-434, 2001.

[37] G. E. Battese and T. J. Coelli, "A model for technical inefficiency effects in a stochastic frontier production function for panel data," Empirical Economics, vol. 20, no. 2, pp. 325-332, 1995.

[38] Z. Wang and J. C. Shi, "Regional differences and volatility of china's industrial production performance during the transition period, an analysis based on the stochastic frontier production function," World Economic Papers, no. 4, pp. 29-45, 2007.
[39] H. F. Yue, "Efficiency measurement of china's green technology innovation based on environmental regulation," Statistics \& Decision, vol. 34, no. 08, pp. 100-104, 2018.

[40] K. X. Bi, Y. H. Wang, and C. J. Yangn, "Impact of innovation resources input on the green innovation ability of green innovation system, an empirical study based on manufacturing FDI inflow," China Soft Science, no. 03, pp. 153-166, 2014.

[41] Z. Y. Zhang and G. Q. Zhao, "FDI, Environmental Regulation and Technological Progress, An Empirical Analysis Based on Chinese Provincial Data," Journal of Quantitative Economics and Technology, vol. 29, no. 04, pp. 19-23, 2012. 


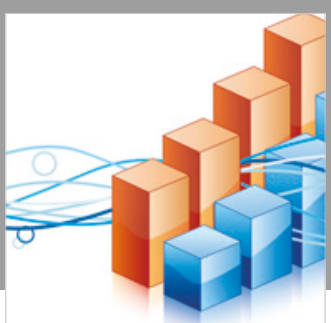

Advances in

Operations Research

\section{-n-m}
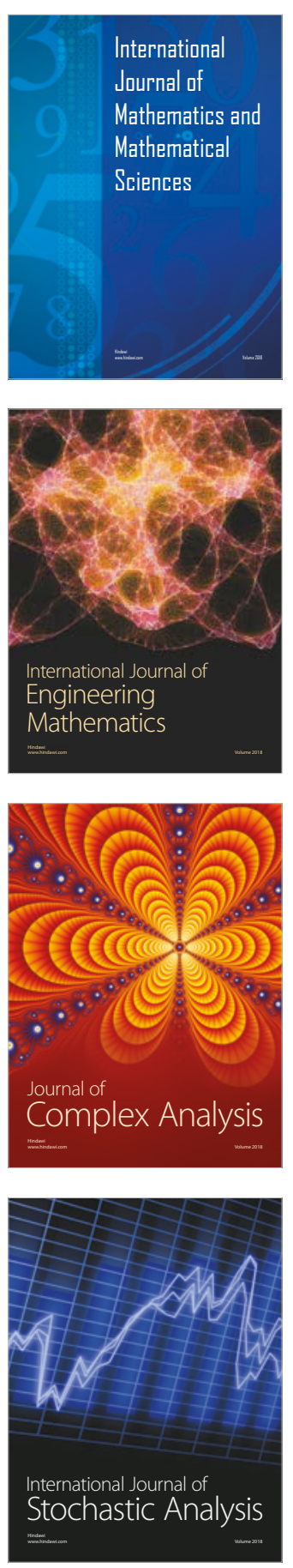
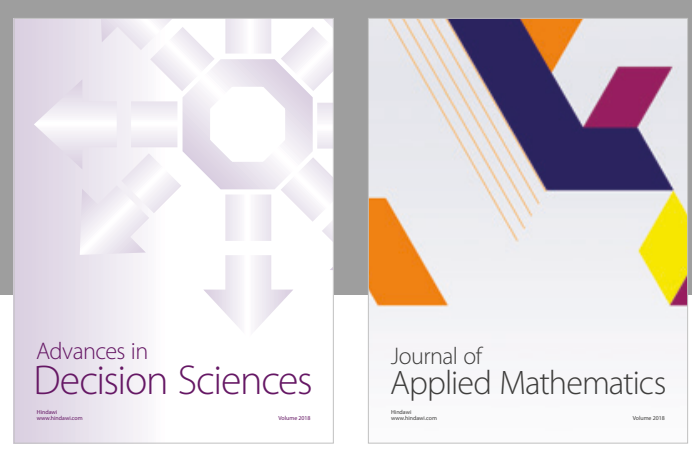

Journal of

Applied Mathematics
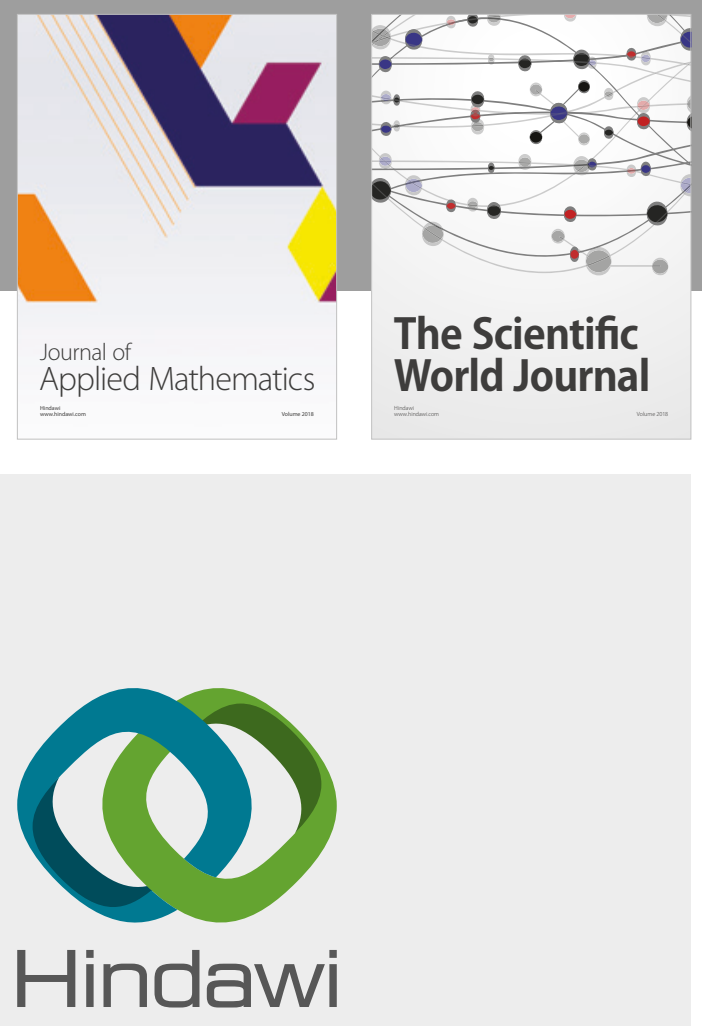

Submit your manuscripts at

www.hindawi.com

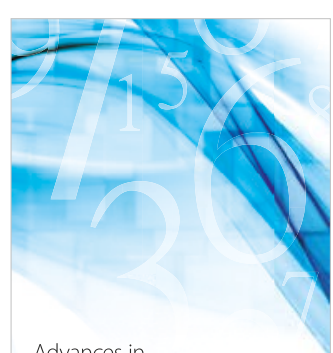

Advances in
Numerical Analysis
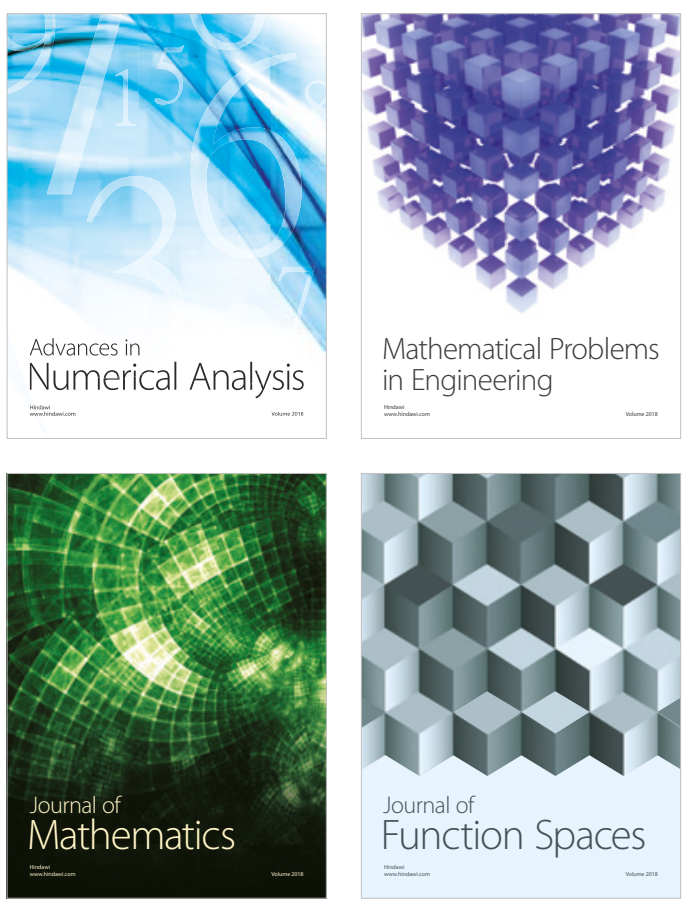

Mathematical Problems in Engineering

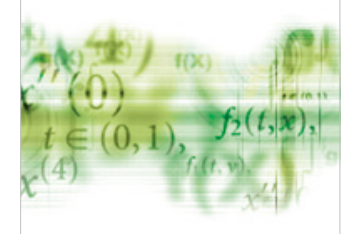

International Journal of

Differential Equations

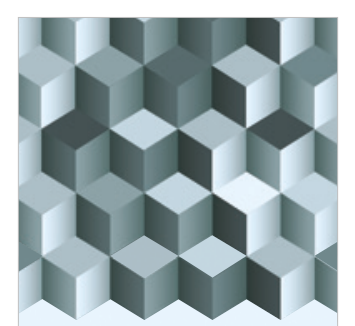

Journal of

Function Spaces

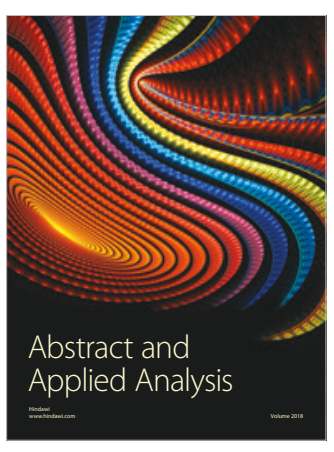

The Scientific

World Journal

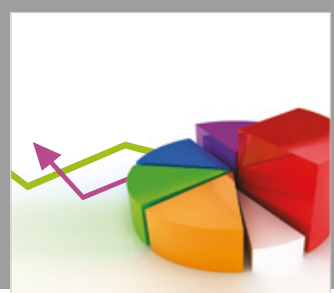

Journal of

Probability and Statistics
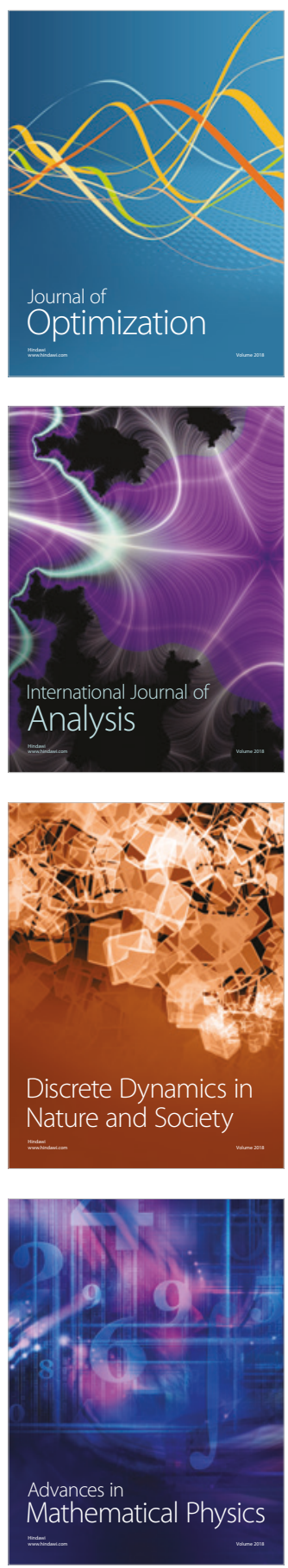